\title{
Informaciones académicas
}

\section{Cuadernos del Clesal \\ Universidad Nacional de Rosario}

El Centro Interdisciplinario de Estudios Sociales Argentinos y Latinoamericanos, CIESAL, de la Universidad Nacional de Rosario, que dirige Ricardo Falcón, editó en diciembre del año pasado el primer número de sus Cuadernos, publicación semestral de estudios multidisciplinarios sobre la cuestión social. Para su presentación se organizó en el Club de Cultura Socialista de Rosario -Librería "Los tiempos modernos"- un panel sobre el tema: Investigación en Ciencias Sociales y estrategias de publicación; en el que Juan Suriano - Entrepasados-y Darío Macor - Estudios Sociales-acompañaron a Ricardo Falcón.

Estudios Sociales considera que la mejor manera de dar la bienvenida a la publicación hermana es reproducir su editorial de presentación.

"Suele decirse que todas las revistas nuevas tienen su historia. Este es, también, el caso de Cuadernos. Esta es una historia que, en sus antecedentes más remotos, remonta a casi diez años. En efecto, a partir de 1984 comenzó a constituirse un grupo informal de investigadores de distintas disciplinas y con diversas pertenencias institucionales, en el seno de la Universidad Nacional de Rosario. A partir de distintos enfoques disciplinarios sobre la cuestión social, tanto en perspectiva histórica como contemporánea, este grupo fue creciendo paulatinamente, a la vez que sus actividades aumentaban en cohesión."

"Sin embargo, por el hecho de carecer de un lugar común, debido a la pertenencia de sus miembros a distintas Facultades e instituciones de investigación, especialmente el CONICET y el CIUNR, no adquiriria un carácter más formal hasta que en diciembre de 1990 , por resolución del Rector de la UNR se crearía el CIESAL, en el seno del Centro de Estudios Interdisplinarios, CEI, dependiente de la Secretaría Académica de la Universidad."

"EI CIESAL, institución dedicada a actividades interdisplinarias de investigación y docencia de posgrado, no se limitó a esas actividades sino que, en la medida que cabia en sus atribuciones y obligaciones, comenzó a desarrollar una cierta actividad editorial con el objetivo, entre otros, de favorecer la divulgación de las producciones de investigación que se desarrollaban en su seno. Así nació Estudios Sociales, coeditada por el CIESAL, el CEDEHIS de la Universidad Nacional del Litoral y el GEHISO de la Universidad del Comahue."

[...] "Hoy, sin abandonar los compromisos con Estudios Sociales, nada impide la aparición de Cuadernos, cuya tarea no es competitiva sino complementaria con la de esa publicación. Prueba de esa complementariedad es que Cuadernos tiene un carácter distintivo. En cada uno de sus números se expresará una preferencia temática, que comprenderá un espacio privilegiado dentro de los estudios multidisciplinarios dedicados a la cuestión social. Asi, en este primer número, la cuestión del trabajo en su noción más lata y la de las relaciones históricas entre el Estado y los movimientos sociales, en particular, constituyen su tema preferencial. El segundo número estará dedicado a la ciudad, a través de distintos enfoques displinarios."

"Además adquiere un segundo carácter distintivo, al centrarse específicamente en la cuestión social, la cual será abordada desde distintos ángulos disciplinarios: económicos, 
jurídicos, sociológicos, históricos, antropológicos, urbanísticos, políticos, filosóficos, culturales, literarios, etc. De esta manera se pretende contribuir a llenar un cierto vacío, en la medida que escasean, a nivel nacional, publicaciones periódicas especificas sobre esta cuestión."

- Cuadernos se presenta como una revista de estricto carácter académico, siendo la excelencia, en ese sentido, el principal criterio de selección de los artículos. Todos los trabajos que se postulen serán sometidos al sistema de arbitraje, según un reglamento elaborado por el Consejo de Redacción, de acuerdo a las normas internacionales al respecto. La existencia de un Consejo Asesor, integrado por reconocidos especialistas, es una garantia en la búsqueda de esa excelencia académica. Los miembros de este Consejo, a pedido del Consejo de Redacción, actuarán como árbitros o podrán sugerir especialistas de su conocimiento para esa tarea."

"Cuadernos es también, en consecuencia, una revista pluralista que admite todas las tendencias académicas e ideológicas democráticas y está abierta, en ese sentido, a todos los enfoques teóricos y metodológicos."

"Su pluralismo no es obstáculo para el compromiso con la ampliación de los espacios de producción académica de investigación en el seno de la Universidad Nacional de Rosario. En este sentido, cada número contendrá una proporción de artículos pertenecientes a jóvenes investigadores rosarinos. Al mismo tiempo, se publicarán trabajos de autores de otras Universidades nacionales y extranjeras."

"En este primer número se reflejan todas esas consideraciones generales. Si bien está dedicado, globalmente, al mundo del trabajo y, en particular, en perspectiva histórica, hay un privilegio temático de la cuestión del Estado y el movimieno obrero, como lo reflejan los trabajos de Juan Suriano, Ricardo Falcón y Alejandra Monserrat, Maricel Bértolo y María Pía Martín. Los lugares se multiplican, combinando estudios de carácter nacional con otros localizados en Buenos Aires y Rosario."

"La diversidad geográfica aparece también en los articulos que están fuera de este subtema, como en el de Darío Macor y Susana Piazzesi, dedicado al poco estudiado tema de los orígenes del movimiento obrero en la ciudad de Santa Fe, o el de Mónica Gordillo sobre un capítulo crucial de la historia sindical y política argentina: el nacimiento del movimiento antiburocrático de la Córdoba de los años sesenta, que luego se proyectaría como un fenómeno nacional."

"El debate teórico internacional aparece con la traducción de Jeremy Adelman que aborda cuestiones vinculadas con problemáticas actuales de primer orden de la historia social latinoamericana. Aun en un número de carácter dominantemente histórico, la multidisplinariedad se expresa con los trabajos de Omar Moreno, hecho desde el ángulo del derecho laboral y tratando temas totalmente contemporáneos, y el de Sandra Caponi que desde la novedosa, para nosotros, "filosofía del trabajo", evoca algunas nociones fundamentales partiendo, entre otros, de Foucault y Thompson."

(...) "Ha sido voluntad de todo el Consejo de Redacción dedicar este número a la memoria de Leandro Gutiérrez, historiador recientemente fallecido y que, poco antes de morir, había aceptado la invitación a ser miembro del Consejo Asesor, en una entusiasta carta en la que nos impulsaba en nuestra empresa. La muerte de Leandro nos dejó sin un colaborador, que sin duda habria hecho aportes sustanciales a nuestra revista, como los hizo durante su vida a la historia social argentina." 


\section{Programa de Estudios Interdisciplinarios de Historia Social Centro de Estudios Históricos Universidad Nacional del Litoral}

El Centro de Estudios Históricos, CEDEHIS, impulsado inicialmente por la cátedra de Historia Argentina Contemporánea del Departamento de Historia de la Facultad de Formación Docente en Ciencias, tiene su sede en esta Casa de Estudios de la Universidad Nacional del Litoral. El conjunto de actividades que se desarrollan en su ámbito están ordenadas, para el bieño 93/95, en el Programa de Estudios Interdisciplinarios de Historia Social, PEIHS, que cuenta con el respaldo académico y financiero de la Secretaría de Investigación Científica y Tecnológica de la UNL.

\section{Actividades de investigación:}

Las actividades de investigación están sistematizadas en dos proyectos en ejecución en el marco del Curso de Acción para la Investigación y Desarrollo (CAID 93/94) de la UNL:

- Actores sociales y políticos en la reconstitución delpoder, 1930-1946. Dirección: Prof. Darío Macor, Facultad de Formación Docente en Ciencias, UNL.

- El mundo urbano santafesino. Continuidades y rupturas en la primera mitad del siglo $X X$. Dirección: Arq. Adriana Collado, Facultad de Arquitectura y Urbanismo, UNL.

\section{Actividades editoriales:}

En el año académico 1993, el CEDEHIS continuó con las tareas inherentes como coeditor de la revista Estudios Sociales, de la que se publicaron los números 4 y 5 correspondientes a su tercer año. Paralelamente se iniciaron dos líneas de publicaciones enteramente propias: libros (Estudios Cedehis) y Documentos de Trabajo:

- La reforma política en la encrucijada. La experiencia demoprogresista en el Estado provincial santafesino (Darío Macor), Estudios Cedehis, UNL.

- Joquín V. González, Hidalgo de provincia (Fabián Herrero), Documento de Trabajo, Peihs/Cedehis, UNL.

Toda correspondencia debe remitirse al director del Centro:

\section{Centro de Estudios Históricos}

Prof. Dario Macor

Facultad de Formación Docente en Ciencias, UNL.

9 de julio 2655 - 3000 Santa Fe, Argentina. 


\section{Concurso de investigación histórica Facultad de Ingeniería Química, UNL.}

En 1994 se cumplen 75 años de la fundación de la Universidad Nacional del Litoral y de la Facultad de Ingenieria Química de esta Universidad. En adhesión a esta conmemoración, la Fundación de la Facultad de Ingeniería Química convoca a un concurso de investigación histórica sobre la historia de la mencionada Facultad.

Tema: Todo lo relacionado con el devenir y desarrollo de la Facultad de Ingeniería de la UNL: aspectos académicos, estudiantiles, del cuerpo de profesores; protagonismo y repercusión en el desarrollo de la ciencia y la investigación; aporte cultural a la ciudad y la región; relaciones con la Escuela Industrial Superior; biografías de profesores del cuerpo académico de la Casa de Estudios; impacto de la institución en el ámbito nacional e internacional; etc. Desde la fundación hasta nuestros días. Igualmente se podrá considerar la evolución del edificio e infraestructura.

Los trabajos deben ser inéditos y con una extensión no menor de 50 páginas ni mayor de 200 impresos en doble interlínea en papel tamaño oficio.

La fecha de cierre para la presentación de trabajos es el 31 de agosto de 1994, habiéndose establecido un primer premio consistente en la publicación de la obra y Diploma de honor.

Información:

Fundación Facultad de Ingeniería Química, UNL Santiago del Estero 2829

Tel. (042) 20010. Fax. (042) 20018 - 553727

(3000) Santa Fe, Argentina. 